\title{
Os fundamentos que sustentaram o surgimento das escolas de reforma no Brasil
}

The elements that supported the emergence of reform schools in Brazil

\author{
Viviani Yoshinaga Carlos $*$ \\ Silvia Alapanian**
}

\begin{abstract}
Resumo:
Neste ensaio, apresentamos os fundamentos ideológicos que derem sustentabilidade para a elaboração e organização das primeiras Escolas de Reforma no Brasil. Precursoras do modelo de socioeducação que temos nos dias de hoje, essas Escolas foram idealizadas a partir dos estudos de médicos e juristas brasileiros, no início do século XX, que justificaram a necessidade de intervenção do Estado face à criminalidade da infância e da adolescência pobres do país, ao defender uma ideia de educação articulada à justiça e à assistência.
\end{abstract}

Palavras-chave: socioeducação; educação; assistência; Escolas de Reforma.

\begin{abstract}
:
In this paper, we present the ideological elements that give sustainability to the preparation and organization of the first Schools Reform in Brazil. Precursor model socioeducation we have nowadays, these schools were developed from studies of doctors and lawyers Brazilian early twentieth century, justifying the need for state intervention in the face of crime of childhood and adolescence poor country defending an idea articulated justice education and assistance.
\end{abstract}

Keywords: socioeducation; education; assistance; Schools Reform

\section{Introdução}

Nossa intenção é compreender e discutir os aspectos históricos que demarcaram a política de atendimento a crianças e adolescentes no Brasil, com o objetivo de aprofundar as questões ideológicas que fizeram surgir o conceito de socioeducação, isto é, um tipo de abordagem ou enfrentamento da questão da criminalidade infanto-juvenil que articula educação, assistência social e punição. Encontramos elementos para essa reflexão em um

\footnotetext{
* Mestre em Serviço Social e Política Social pela Universidade Estadual de Londrina. Docente do curso de Serviço Social da Faculdade Estadual de Ciências Econômicas de Apucarana. E-mail: vyoshinaga@fecea.br

** Doutora em Serviço Social pela Pontifícia Universidade Católica de São Paulo. Docente do curso de Serviço Social da Universidade Estadual de Londrina. E-mail: silviaal@uel.br
} 
estudo de natureza histórica, a partir do surgimento das primeiras Escolas de Reforma no Brasil, no início do século XX.

A política de assistência a menores ${ }^{1}$ foi delineada, no Brasil, a partir de experiências advindas de modelos europeus e norte-americanos. A transição do século XIX para o século XX marcou um período de mudanças econômicas, políticas e sociais nos países industrializados, que teve reflexos no Brasil. Netto (2001) destaca que essas mudanças trouxeram uma nova dinâmica do Estado diante do capitalismo de monopólios. Urgia a necessidade de uma demarcada intervenção estatal, que conciliasse suas funções políticas, econômicas e sociais, mantendo, num primeiro momento, seu caráter liberal.

No Brasil, a visão de um Estado Liberal conciliador começa a ser percebida durante a Primeira República, ainda que de forma incipiente, em um momento em que a industrialização e a urbanização foram lançadas como expressão do progresso e da modernidade, mas acabaram por revelar os conflitos sociais da época. Emergem, desta forma, no início do século $X X$, as primeiras iniciativas que reclamam a intervenção do Estado face aos problemas sociais, entre elas, as que identificam os menores como objeto da tutela estatal.

De acordo com Rizzini (2009), na primeira década do século XX, foram criados, pelos governos de diversos estados do país, institutos disciplinares para atender os menores abandonados e delinquentes. Destacam-se, nesse período, o Instituto Disciplinar, criado em 1902, na cidade de São Paulo, a Escola XV de Novembro, criada em 1903, no Rio de Janeiro, e, em 1909, o Instituto João Pinheiro, em Minas Gerais.

Nesses institutos, eram internados os menores abandonados que, devido a seus comportamentos, foram considerados "desajustados", uma vez que a interpretação médica e jurídica da época apontava o abandono material como causa de "vícios", "vadiagem", "mendicância", "libertinagem" e "prostituição".

Assim, refletir sobre o conceito de socioeducação que utilizamos nos dias atuais implica discutir os argumentos segundo os quais o Estado criminalizou a infância pobre do país no início do século XX, definindo tipos de educação para os menores pobres diferentes da educação destinada a crianças e adolescentes das demais classes sociais. Elegiam-se, à

\footnotetext{
${ }^{1}$ A expressão "menor" será largamente utilizada ao longo deste texto, numa perspectiva histórica, uma vez que estamos nos referindo a autores que representam o ideário de uma época, quando crianças e adolescentes foram objeto da reflexão de juristas, como parte de uma demanda do Estado.
} 
época, os Institutos Disciplinares e Correcionais como estabelecimentos educacionais para os menores abandonados e as Escolas de Reforma para os menores delinquentes.

Apresentamos, primeiramente, as premissas que sustentavam o modelo educacional, em fins do século XIX, no mundo e no Brasil. Num segundo momento, apresentamos as ações de assistência aos pobres, no mesmo período, para buscar, na síntese entre essas duas políticas, o surgimento das primeiras Escolas de Reforma, precursoras das ações de atenção a adolescentes em conflito com a lei, na atualidade.

\section{O modelo liberal de educação}

O ideário liberal sustenta a crença de que a educação é um meio eficaz e disponível para que as pessoas possam melhorar sua posição social. De acordo com Cunha (1975), o papel atribuído à educação pela doutrina liberal é o de um instrumento para a construção de uma sociedade aberta, ou seja, para a construção do progresso individual e geral. Tal premissa sustenta-se nos cinco princípios básicos do liberalismo: individualismo, liberdade, propriedade, igualdade e democracia. A realização desses princípios, que mantêm uma interdependência, resultaria em uma sociedade aberta, onde todos teriam iguais oportunidades de ocupação das posições sociais existentes.

Com essas ideias, após séculos de sujeição feudal, a burguesia afirmava os direitos do indivíduo como premissa necessária para a satisfação de seus interesses. Liberdade absoluta para contratar, comerciar, crer, viajar e pensar. As bases para que um novo modelo de educação fosse pensado, a fim de satisfazer as necessidades do homem burguês, foram firmadas de acordo com as exigências do mercantilismo e de sua expansão durante os séculos XV a XVIII.

Os teóricos do liberalismo que mais contribuíram para o pensamento pedagógico burguês foram Locke, Rousseau, Voltaire e Diderot, nos séculos XVII e XVIII. A ideia de reconstrução individual, no sentido de aperfeiçoamento moral, orientava o pensamento da época.

Apesar de ter se consagrado muito mais como teórico/político liberal, John Locke (1632-1704) apresentou conceitos educacionais importantes para uma nova visão da escola, que não fosse instrumento das classes dominantes de sua época. 
De acordo com Cunha (1975), Locke entendia que todos os indivíduos eram iguais ao nascer, sejam ricos ou pobres, escravos ou rei. Em sua concepção, as diferenças entre os homens eram causadas pela educação. Entretanto, Locke não era favorável à universalização da educação; embora reconhecesse que os indivíduos fossem iguais, sejam ricos ou pobres, o teórico liberal admitia que a ordem social já se apresentava estabelecida, o que distinguia ricos e pobres quanto à instrução que deveriam receber.

O modelo educativo elaborado por Locke manifestava, de forma exemplar, os elementos fundamentais da educação burguesa, baseada nas virtudes sociais, na utilidade, no primado da consciência moral e na valorização da natureza e da razão. Sobre a educação do povo, Locke sugeriu ações caritativas ou escolas de trabalhos forçados para rapazes pobres (CAMBI, 1999).

Pertencente a uma geração posterior, François Marie Arouet Voltaire (1694-1778) era filho de aristocratas e seu pensamento refletia os interesses da alta burguesia e da nobreza. Apesar de ter sido um dos principais pensadores do movimento liberal na França, seu pensamento evidenciava um profundo respeito à ordem estabelecida. Dessa maneira, Voltaire também via a educação como privilégio de poucos (CUNHA, 1975).

Ao contrário de Voltaire, Denis Diderot (1713-1784) incentivava a instrução das massas. Seu pensamento refletia as aspirações dos artesãos e dos operários, demonstrando insatisfação com as injustiças de sua época. Na polêmica entre os ideais de Voltaire e Diderot, temos o posicionamento deste último: "É bom que todos saibam ler, escrever e contar, desde o primeiro ministro ao mais humilde dos camponeses. [...] Porque é mais difícil explorar um camponês que sabe ler do que um analfabeto" (DIDEROT apud PONCE, 2001, p. 133).

Nessa mesma perspectiva de instrução das massas, mas com pretensões diferentes, encontram-se também as ideias de Adam Smith (1723 - 1790). Diferente de Diderot, cujo pensamento se afinava com as insatisfações dos operários de sua época, Adam Smith alertou, em sua obra, Riqueza das Nações, de 1776, que a instrução do povo evitaria as desordens sociais e que um povo instruído e inteligente seria mais decente que um povo ignorante e obtuso (CUNHA, 2000).

Todavia, tais pensadores ainda viam, de forma limitada, o papel social que o liberalismo reservava para a educação: instrumento de ascensão social e equalização de 
oportunidades. Foi a partir do pensamento de Basedow e Filangieri que o projeto educacional da burguesia revolucionária se expressou, passando a orientar-se para a ideia de reconstrução social.

Basedow (1723-1790) foi um educador ativo, preocupado com as questões de sua época, defendia que a finalidade da educação consistia em formar "cidadãos do mundo e em prepará-los para uma existência útil e feliz" (BASEDOW, 1774 apud PONCE, 2001, p.137). Para tanto, distinguia dois tipos de escolas: uma para os pobres e outra para os filhos dos cidadãos mais eminentes. Em suas palavras:

Não há nenhum inconveniente em separar as escolas grandes (populares) das pequenas (para os ricos e também para a classe média), porque é muito grande a diferença de hábitos e de condição existentes entre as classes a que se destinam essas escolas. Os filhos das classes superiores devem e podem começar bem cedo a se instruírem, e como devem ir mais longe do que os outros, estão obrigados a estudar mais. As crianças das grandes escolas (populares) devem, por outro lado, de acordo com a finalidade a que deve obedecer a sua instrução, dedicar pelo menos metade do seu tempo aos trabalhos manuais, para que não se tornem inábeis em uma atividade que não é tão necessária, a não ser por motivos de saúde, às classes que trabalham mais com o cérebro do que com as mãos (BASEDOW, 1774, p.41 apud PONCE, 2001, p.137).

Basedow argumentava que, nas grandes escolas, os mestres deveriam, além de ensinar a ler, a escrever e a contar, cuidar dos deveres que são próprios das classes populares, dedicando tempo aos trabalhos manuais. Segundo ele, "Felizmente, as crianças plebeias necessitam de menos instrução do que as outras, e devem dedicar metade do seu tempo aos trabalhos manuais" (BASEDOW, 1774, p. 51 apud PONCE, 2001, p.137).

Filangieri (1752-1788) também se expressava de forma semelhante. De acordo com seu pensamento, o agricultor, o ferreiro,

[...] não necessitam mais do que uma instrução fácil e breve para adquirir as noções necessárias para a sua conduta civil e para os progressos da sua arte. Não se poderia dizer o mesmo em relação aos homens destinados a servir a sociedade com os seus talentos (FILANGIERI, 1780 apud PONCE, 2001, p. 137).

Para Filangieri, a educação pública exige, para se tornar universal, que todos os indivíduos da sociedade participem dela, mas cada qual de acordo com as circunstâncias e com o seu destino. Assim, afirmava que "o colono deve ser instruído para ser colono e não para ser magistrado" (FILANGIERI, 1780 apud PONCE, 2001, p. 137). 
Condorcet (1743-1794), importante teórico da educação liberal, defendeu que o Estado deveria assegurar a cada cidadão o gozo de seus direitos, intervindo na supressão das desigualdades artificiais ou sociais (desigualdade de riqueza, desigualdade de profissão, desigualdade de instrução), consequência da reunião dos homens em sociedade. Para combater a desigualdade de instrução, Condorcet defendia a organização de um ensino público, livremente aberto para todos, ou seja, gratuito.

De acordo com seu pensamento, a instrução das crianças deveria ser assumida pelo Estado e retirada da responsabilidade exclusiva dos particulares. Ao Estado caberia o controle do ensino e a instrução de crianças; a educação ficaria a cargo da família e da formação religiosa. O Estado deveria ensinar apenas as ciências positivas. Em sua opinião, a instrução pública deveria assegurar a todos um mínimo de cultura, para "que não deixe passar despercebido qualquer talento, e possa oferecer-lhe todos os recursos que até agora só estavam ao alcance dos filhos dos ricos" (CONDORCET apud PONCE, 2001, p.139).

Com a eclosão da Revolução Francesa, Condorcet foi eleito, em 1789, deputado por Paris à Assembleia Legislativa, e depois, eleito por cinco departamentos à Convenção. Foi encarregado de redigir um projeto relativo à instrução pública na França, conhecido como Rapport. Em síntese, o Rapport estabelecia: a criação de um ensino elementar, comum a todas as pessoas, sem distinção de ordem e fortuna; a instrução técnica com vistas a uma profissão determinada; e o desenvolvimento pleno dos diversos talentos pessoais. Para tanto, a instrução deveria variar segundo a natureza e o potencial de cada indivíduo e ser proporcional ao tempo que cada um, segundo sua situação econômica, pudesse dedicar aos estudos (PONCE, 2001).

Lepelletier (1760-1793), político francês, tornou-se adepto da Revolução Francesa, sendo eleito, em 1789, presidente da Assembleia Constituinte e depois deputado à Convenção. Elaborou um Plano Nacional de Educação apresentado e defendido por Robespierre na Convenção, em 1793, que foi aprovado pela Assembleia, mas não foi posto em prática (CUNHA, 1975).

O Plano de Lepelletier também defendia, como os demais projetos da época, a gratuidade, a igualdade e a obrigatoriedade do ensino, que deveria ser promovido pelo Estado às crianças de até 12 anos de idade. Segundo Cunha (1975), Lepelletier reconhecia a utilidade da educação para o novo regime político e social e a apontava como dívida da 
República para com todos. Os objetivos de seu plano eram: fortificar o corpo e desenvolvêlo por meio de exercícios de ginástica; acostumar as crianças ao trabalho das mãos; endurecê-las contra toda espécie de cansaço; dobrá-las ao jugo de uma disciplina salutar; formar-Ihes o coração e o espírito por meio de instruções úteis; e dar conhecimentos necessários a todo cidadão, seja qual for sua profissão.

Discípulo da Revolução Francesa, Pestalozzi (1746-1827) ficou conhecido como educador da humanidade e teve influência na estruturação de um determinado modelo de educação de tipo assistencial. Interessou-se pela educação dos camponeses, mas, ainda que esse sentimento tenha sido autêntico e generoso, passou a vida educando crianças ricas. Segundo Ponce (2001), nas poucas vezes em que Pestalozzi acolheu crianças pobres, em sua casa, com a intenção de educá-las, ele atuou como filantropo e industrial.

Pestalozzi admitia que a organização burguesa e todos os seus males haviam sido criados por Deus. Desta forma, a ordem social determinaria diferentes tipos de educação, conforme a classe social. Assim, o filho do aldeão deve ser aldeão, e o filho do comerciante, comerciante. A educação do povo defendida por Pestalozzi teve um caráter "manso", conforme assevera Ponce (2001), pois apenas pretendia educar os pobres para que aceitassem sua pobreza.

Apesar de ter educado algumas crianças pobres e de ter recolhido muitas outras em seu orfanato, Pestalozzi não lhes oferecia a mesma educação que ministrava às crianças ricas. Também não pensava em educar crianças ricas por meio do trabalho. Dividia o seu ensino e o seu método de acordo com a classe social a que pertenciam seus educandos.

Dessa mesma geração, o francês Jean-Baptiste Say (1767-1832), discípulo de Adam Smith, dizia, em 1803, que a educação dos operários era uma imposição decorrente da divisão do trabalho. Segundo ele, a repetição do trabalho manual embrutece o operário, uma vez que dispensa o uso da inteligência. Um mínimo de instrução seria necessário para manter a ordem das relações estabelecidas.

Por sua vez, Robert Malthus (1766-1834) defendia o trabalho obrigatório, pois somente assim se poderia evitar uma crise econômica e social, uma vez que, segundo sua tese, a população crescia mais rapidamente que a produção. Para Malthus, a assistência aos pobres era uma forma de induzi-los à ociosidade. A educação aos pobres era necessária, desde que fossem abolidas as práticas caritativas. 
François Pierre Guillaume Guizot (1789 -1874) foi, por fim, quem cristalizou as propostas educacionais dos ideólogos da burguesia vitoriosa do século XVIII, através do célebre epigrama: cada escola aberta fecha uma prisão. Instruir as massas era, para ele, uma forma de prevenir "as insurreições e as transgressões das normas sociais, dispensando o Estado de manter um grande e dispendioso aparelho repressivo" (CUNHA, 2000, p. 148).

Assim, com o amadurecimento e a consolidação do processo de industrialização, a partir da segunda metade do século XIX, fica clara, para a burguesia, a importância da educação das massas, dos trabalhadores. A burguesia não podia recusar a instrução do povo, assim como o fizeram as elites na antiguidade e no feudalismo (PONCE, 2001); as máquinas criadas pela indústria eram complicadas demais para serem operadas pelo mísero saber dos trabalhadores da época. Para manejar certas ferramentas, era necessário aprender a ler.

Nunca foi tão evidente a diferença entre trabalhadores não especializados, capazes apenas de realizar as tarefas mais grosseiras, e trabalhadores especializados, encarregados de tarefas que exigem um nível mediano de cultura. Entretanto, ao lado desses dois tipos de trabalhadores, o capitalismo ainda requeria outra espécie de trabalhador: um operário altamente especializado, detentor de uma cultura excepcional.

De acordo com Ponce (2001) o progresso da química, por exemplo, ampliava a sua utilização e a de seus recursos e materiais, além de estender as possibilidades de aplicação de capital. A livre concorrência exigia não só o aperfeiçoamento constante das técnicas de produção, como também a necessidade permanente de invenções. Para tanto, a livre investigação era imprescindível para o capitalismo, pois, como afirma Ponce (2001, p.146), "favorecer o trabalho científico, mediante escolas técnicas e laboratórios de altos estudos, foi, desde essa época, uma questão vital para o capitalismo".

Tanto as escolas tradicionais quanto as criadas sob a influência direta da Revolução Francesa não estavam em condições de satisfazer essa exigência. Junto às fábricas, fruto direto da iniciativa privada, surgiram, então, as escolas politécnicas. A burguesia do século XIX preparava, nessas escolas, seus peritos industriais, assim como, no século XVI, havia preparado, em suas escolas comerciais, seus peritos mercantis (PONCE, 2001). Uma educação primária para as massas e uma educação superior para os técnicos era o que a burguesia exigia no campo da educação. 
Ao lado das escolas industriais e superiores, destinadas a preparar capatazes e técnicos do exército industrial, a burguesia reservou para seus filhos outro tipo de ensino, inteiramente separado do trabalho, que considerava como o único tipo de ensino verdadeiramente digno das classes superiores. O ensino secundário deveria capacitar as classes médias "a guiar a vontade nacional". (PONCE, 2001, p. 149).

As contradições da burguesia revelavam-se de forma clara no seu plano pedagógico. Se, de um lado, havia a necessidade de instruir as massas, para que estas atingissem o nível exigido pelas técnicas da nova produção, de outro, havia o medo de que essa mesma instrução pudesse torná-las menos passivas. Para resolver esse conflito de forma a conservar seus interesses, a burguesia propôs dosar o ensino primário, dotando-o de um espírito de classe, a fim de não comprometer a exploração do operário, base de sua existência.

Segundo Ponce (2001), por volta de 1880, as aspirações da burguesia, na área da educação, aplicadas de maneira empobrecida por Pestalozzi e seus discípulos, já podiam ser vistas de forma mais concreta: "o advento da escola laica, conseguido por essa época após violentos debates, punha de certo modo, à batalha empreendida alguns séculos atrás com a intenção confessada de arrebatar à Igreja o controle do ensino" (PONCE, 2001, p.153).

As transformações capitalistas próprias da passagem da era concorrencial à monopolista, na transição do século XIX para o século XX, vão encontrar, nas ideias do filósofo John Dewey (1859-1952), uma proposta de educação destinada à reconstrução da sociedade, de forma democrática. Trata-se do modelo conhecido como pedagogia da escola nova (escolanovista).

Dewey compreendia que, à medida que a sociedade se tornava democrática (aberta), a educação deveria fornecer os elementos necessários para o desenvolvimento da iniciativa individual e da adaptabilidade. A escola deveria ter a preocupação de exercer a capacidade de readaptação do aluno às condições de vida e de desenvolvê-lo nos aspectos intelectuais. A educação deveria ser, portanto, um instrumento de equalização de oportunidades, não de reprodução das diferenças individuais (CUNHA, 1975).

A trajetória do pensamento liberal é sintetizada por Cunha (1975) quando afirma que o principal ideal liberal da educação é o de que a escola não deve estar a serviço de 
nenhuma classe, de nenhum privilégio, credo religioso ou político. A instrução não deve estar reservada apenas às elites ou às classes superiores, nem ser um instrumento aristocrático para servir a quem possui tempo ou dinheiro. A educação deve estar a serviço do indivíduo, do homem total, liberado e pleno. Para tanto, a escola deve ser pública, universal e gratuita, a fim de proporcionar a igualdade de oportunidades e de direitos.

A escola, assim, preocupada com o homem, independente da família, classe ou religião a que este pertença, irá revelar e desenvolver os dotes inatos, os valores intrínsecos, as aptidões, talentos e vocações ${ }^{2}$ dos indivíduos. É a partir dos talentos e vocações individuais que o sujeito adquirirá sua posição social, isto é, irá encontrar seu lugar na estrutura ocupacional existente.

A educação, na concepção liberal mais comumente expressa, não considera as classes de origem dos alunos e os privilégios. Trata-os igualmente, procurando habilitá-los a participar da vida social conforme o mérito individual. Assim, a ascensão social do indivíduo, ou seu oposto, estará condicionada à sua educação ou nível de instrução.

Há que se considerar, porém, a ferrenha crítica de Ponce (2001) sobre essa "neutralidade escolar":

Sabemos o que significa nas mãos da burguesia 'liberdade da criança', 'formação do homem', 'direitos do espírito'. A imagem do novo homem que a burguesia nos prometia é a velha imagem já bem nossa conhecida: a de uma classe opressora que monopoliza a riqueza e a cultura diante de uma classe oprimida, para a qual só é permitida a superstição religiosa e um saber bem dosado (PONCE, 2001, p. 172).

Para o autor, a finalidade do modelo escolar proposto pela burguesia é defender os seus interesses mediante a preparação da mentalidade e da conduta das crianças. Essa forma de disciplina vai se coadunar com as necessidades do capitalismo em sua nova fase, a era dos monopólios.

O acelerado ritmo econômico e social dessa fase do capitalismo exigiu a expansão da atuação do Estado sobre os focos de desordem que se instalavam nas sociedades capitalistas, resultantes do crescimento urbano desenfreado. De acordo com Braverman (1987), dentre os serviços ofertados pelo Estado, a educação foi vista como o mais

\footnotetext{
2 Assumindo uma posição mais secular e utilitária, o liberalismo afirma que a vocação é a realização individual para a construção do progresso geral (CUNHA, 1975).
} 
importante, ampliando o seu papel na era dos monopólios. O cuidado e a socialização das crianças foram se afastando do ambiente familiar e comunitário e se tornando, cada vez mais, institucionalizados. Os serviços educacionais assumiram, desta forma, não só a função de prover as necessidades ocupacionais da sociedade capitalista, mas, principalmente, de introjetar os valores para o trabalho e para o consumo condizentes com as necessidades daquele tipo de capitalismo. De acordo com Braverman:

O requisito mínimo para 'funcionar' num ambiente urbano moderno - tanto como trabalhadores quanto como consumidores - é comunicado às crianças num aparelho institucional mais do que na família ou na comunidade. Ao mesmo tempo, o que a criança deve aprender já não é mais uma adaptação ao trabalho lento e temporário no meio natural imediato, mas uma adaptação à veloz e intricada maquinaria social (BRAVERMAN, 1987, p. 244-245).

O autor ressalta que os modos de vida no ambiente urbano moderno eram estabelecidos de forma padronizada e mecânica, e acabavam por definir rotinas não só para o trabalho nas fábricas como também para as formas de divertimento. Neste contexto, a escola apresenta-se como o local privilegiado para o aprendizado de rotinas e sua conformidade, a fim de manter a ordem da sociedade burguesa. Assim, a escola pública, gratuita e universal, torna-se responsável pela socialização das crianças e adolescentes, ou seja, pela adaptação às normas, à vida em sociedade, equalizando as oportunidades para a ascensão social.

\section{A educação liberal no Brasil}

O pensamento e a prática pedagógica constituídos no Brasil são produtos da realidade nacional e devem ser compreendidos a partir da singularidade da formação social brasileira, que, conforme assevera Xavier (1990), permitiu tornar compatível o discurso liberal, típico dos países capitalistas avançados, com a realidade de um país economicamente atrasado e dependente.

A doutrina liberal chegou ao Brasil ainda no período imperial, através dos discursos traduzidos que inspiravam os intelectuais da época e que formaram o ideário liberal nacional. Enquanto ideologia nacional, o liberalismo foi necessário para a introdução do capitalismo no Brasil e para a formação de uma ideologia educacional no país. 
O percurso ideológico da elite intelectual brasileira acompanhou as vias particulares de penetração e de consolidação do capitalismo no país. As pressões para a abolição da escravatura, que marcaram o final do Império brasileiro, contribuíram para que se desenvolvesse uma consciência pedagógica correspondente ao avanço das relações capitalistas de produção em nosso país.

Com a pressão dos ingleses para o fim do tráfico negreiro, a elite intelectual brasileira, representante dos interesses dominantes, passou a defender não só a necessidade de libertar os escravos, como também, de educá-los para serem livres, ou seja, para aceitarem as relações capitalistas de produção. A força de trabalho escrava somente se converteria em força de trabalho livre se este fosse visto como um dever. Para tanto, era preciso educar as massas.

Segundo Cunha (2000), a proposta de um ensino profissional para as massas, moralizante, capaz de desenvolver a produção para transformar a sociedade sem alterar a ordem social, foi o centro do pensamento elaborado no Brasil Imperial para a educação popular. As matrizes ideológicas da educação do povo, que serviram de fonte para os intelectuais do Império, foram elaboradas pelos grandes expoentes do pensamento europeu dos séculos XVIII e XIX, como Adam Smith e Voltaire, que defendiam uma proposta de educação para as massas que não colocasse em risco a ordem social vigente.

Motivados pelas ideias de tais pensadores, em um contexto de pressão interna e externa para a abolição da escravatura, os intelectuais do Império brasileiro debruçaramse sobre propostas para uma educação popular, como forma de se preparar para enfrentar os problemas do progresso. A aprendizagem de ofícios, a que eram submetidos os órfãos, os abandonados e os miseráveis, converteu-se em um tipo de ensino profissionalizante para a formação de uma força de trabalho industrial que emergia no país.

O ensino profissional era tido como uma garantia social, isto é, como uma salvação do futuro. De acordo com Cunha (2000), a experiência dos países civilizados que se preocuparam com a educação popular demonstrava o efeito desta para a sociedade: prosperidade industrial, melhoria da sorte da classe operária e aumento da riqueza pública. Aqui se reproduzia a ideia de que esse tipo de educação representava um regime de igualdade de oportunidades. 
O pensamento liberal, porém, somente se consolidou, no Brasil, a partir da República, com um século de atraso em relação aos países centrais. Segundo Xavier (1990), o desdobramento do liberalismo nacional em um liberalismo educacional representou o esforço empreendido pela consciência pedagógica brasileira em adequar o limitado sistema de ensino às condições sociais e ideológicas das relações capitalistas de produção que passaram a atingir um novo patamar no Brasil ${ }^{3}$.

A escola primária converteu-se no principal ponto de preocupações de educadores e homens públicos da República, conforme expõe Nagle:

[...] procurou-se justificar e difundir o seu caráter obrigatório, apesar do princípio da 'liberdade espiritual', ainda apregoado; procurou-se, em especial, mostrar o significado profundamente democrático e republicano, quando comparado à escola secundária e superior, pois é por meio dela que a massa se transforma em povo e contribui para diminuir o fosso existente entre 'povo' e 'elite' - causa de muitos males - ao fornecer a esta recursos mais sólidos de atuação (NAGLE, 2001, p. 152).

A escola primária possuía uma função estratégica, revestida de um espírito democrático, pois possibilitava à massa a instrução necessária para a reprodução das relações capitalistas de produção, já em sua fase madura. Ao lado da escola primária, com igual importância, encontrava-se a escola técnica-profissional.

Segundo Nagle (2001), durante a Primeira República, a organização do ensino técnico-profissional ficou sob a responsabilidade do Ministério da Agricultura, Indústria e Comércio, conforme estabelecia o Decreto 1.606, de 29 de dezembro de 1906.

Em 1909, foram criadas as Escolas de Aprendizes Artífices, por meio do Decreto 7.566, de 23 de setembro do mesmo ano, que oficializou o ensino técnico-profissional no país. Essas escolas ficaram subordinadas ao Ministério da Agricultura, Indústria e Comércio e destinavam-se a ministrar o "ensino profissional primário gratuito" aos menores que pretendessem aprender um ofício, tendo preferência "os desfavorecidos da fortuna", como apontam os artigos 1ㅇ e 60 do referido Decreto (NAGLE, 2001).

\footnotetext{
${ }^{3}$ Embora tenha influenciado intelectuais brasileiros ao longo dos séculos, a ideologia liberal penetrou efetivamente a sociedade brasileira a partir da década de 1920, convertendo-se em uma ideologia educacional no momento em que o capitalismo se consolidava na transição para a fase industrial. A modernização econômica implicou uma modernização cultural e institucional, fazendo com que a escola assumisse a sua feição liberal rumo à construção de uma sociedade aberta (XAVIER, 1990).
} 
Justificava-se, dessa forma, a importância de organizar um ensino profissional destinado aos pobres. Contudo, este tipo de ensino não se configurava como um programa educacional propriamente dito, conforme esclarece o autor. Apresentava-se mais como um plano assistencial aos necessitados da misericórdia pública, no qual predominava a ideia de regeneração pelo trabalho.

Estrategicamente, as reformas e planos que se sucederam, na década de 1920, começaram a associar a escolarização primária e o ensino "prático", conforme o autor (NAGLE, 2001). Neste momento histórico, difundiu-se a ideia de que a educação forma o homem na medida em que o transforma em um elemento de produção, necessário à vida econômica do país e importante para a elevação dos padrões de vida individuais.

A implantação de novos pré-requisitos para o desenvolvimento do capitalismo no Brasil despertou ainda mais o interesse pelo ensino técnico-profissional, responsável pela formação de uma mão de obra nacional e pela transformação da civilização brasileira em uma civilização eminentemente "prática", assim como eram as modernas civilizações do mundo contemporâneo.

A partir de 1920, a sociedade brasileira não apenas entrou em contato com o ideário liberal escolanovista, de forma sistematizada, como conferiu à educação dos novos tempos uma relevância inusitada. O entusiasmo pela educação e o otimismo pedagógico decorriam da crença de que era possível reformar a sociedade pela reforma do homem. Neste contexto, a escolarização passou a ter um caráter regenerador, em busca da desejada reconstrução nacional proposta pela República, ou seja, um papel insubstituível, pois se trata do motor da história, do instrumento do progresso histórico (NAGLE, 2001).

O lento crescimento industrial do país, apesar de não exigir, naquele momento, uma qualificação para o trabalho, representava um salto qualitativo nas relações de produção. A aceleração do processo imigratório não só estimulava o crescimento industrial e a oferta de mão de obra qualificada, mas também fortalecia a difusão da ilusão liberal de ascensão social pela escolarização.

As elites progressistas encarregaram-se de respaldar, ideologicamente, essa aspiração social via escolarização, pressionando o Estado e atribuindo importância cada vez maior ao tema da instrução, em seus diversos níveis e tipos. A mobilização em torno de 
reivindicações educacionais era oportuna às elites num período em que a crise da atividade agroexportadora ameaçava o poder e a concentração da riqueza. De acordo com Xavier:

\begin{abstract}
Do ponto de vista das classes dominantes cumpria, como sempre o fizera no passado e o faria frequentemente no futuro, a função de canalizar as insatisfações sociais face um estado crônico de carência e exploração, sempre incompreendido e nunca resolvido. Daí o sucesso e a incorporação definitiva dos pressupostos educacionais liberais na crença das camadas subalternas inquietas, mas ignorantes das verdadeiras causas da miséria, no discurso das camadas médias mais sequiosas de participação nos privilégios do que de eliminação dos mesmos e da estrutura que os sustentava; e na retórica das camadas dirigentes, que exploravam e alimentavam essas ilusões. Afinal, expandir as oportunidades educacionais ou reformar as instituições escolares representava um custo menor que alterar a distribuição de renda e as relações de poder (XAVIER, 1990, p. 63).
\end{abstract}

Segundo a autora, apesar do empenho das elites em difundir a ilusão liberal, o liberalismo não afetou, de forma significativa, as instituições educacionais brasileiras e as expectativas sociais quanto à escolarização durante a transição para a fase industrial. As ilusões de ascensão ocupacional, via ascensão escolar, esbarraram nos limites econômicos da realidade nacional e nos privilégios das classes dominantes. Além disso, ao atribuir importância ao processo de escolarização e profissionalização, restringiu-se o processo de educação em um programa de formação, de instrução, desvinculado dos problemas de outra ordem. Por fim, os ideais liberais de uma escola "redentora", responsável pelo progresso individual e social, traduziram-se na ampliação de um sistema tradicional que reproduziu a lógica dominante a partir das elites já existentes anteriormente (XAVIER, 1990).

A partir da segunda década do século $X X$, as tentativas de mudanças na área acontecem de maneira tímida, sem romper com os modelos tradicionais até então empregados no país. De acordo com Nagle:

Profissionalizar a escola primária e disseminar o ensino técnico-profissional significa restringir as possibilidades de uma escolarização mais 'formadora', de acordo com os padrões dominantes na escola secundária; adotar essas posições, independentemente do modo de ligação existente entre a escola primária, a técnica-profissional e a secundária, significa aumentar a distância entre os quadros de formação da 'elite' e os de formação do 'povo' (NAGLE, 2001, p.155).

O ensino primário e o profissionalizante foram destinados ao povo. A educação secundária, preparatória para o ensino superior, era mérito da elite. Os efeitos do 
entusiasmo pela educação e do otimismo pedagógico esbarravam nos limites dos padrões tradicionais de ensino e cultura da escola secundária.

As propostas educacionais que se apresentaram durante o período da Primeira República não avançaram, de maneira incisiva, sobre as bases tradicionais do ensino secundário.

Vários projetos de reforma foram pensados com o intuito de reorganizar o sistema escolar brasileiro. Uma dessas reformas foi a proposta por Rivadávia Corrêa, em 1911, que instituiu a Lei Orgânica do Ensino Superior e do Fundamental, por meio do Decreto no 8.659, de 5 de abril do mesmo ano. Pretendia-se que o curso secundário se tornasse formador do cidadão, não sendo apenas o promotor para o ensino superior. Tendo em vista a orientação positivista, buscava-se o fim do status oficial do ensino, isentando o Estado de tal responsabilidade. De acordo com Cury (2009), os resultados desta Reforma foram desastrosos para a educação brasileira.

Foi somente com a aprovação da Lei Orçamentária, em 1923, que a reorganização do sistema escolar brasileiro foi realmente possível. O então Ministro da Justiça e Negócios Interiores ${ }^{4}$, João Luiz Alves, provocou um movimento da opinião pública para a elaboração de uma nova lei escolar, a partir do projeto de reforma preparado por Ramiz Galvão, presidente do Conselho Superior do Ensino.

A chamada Reforma João Luiz Aves, implantada pelo Decreto 16.782-A, de 13 de janeiro de 1925, reorganizou o ensino secundário, estabelecendo um regime seriado, porém, ainda permaneciam todos os favorecimentos de classe.

Esta Reforma foi considerada a medida educacional mais ampla da União no período, pois nela figuraram dispositivos sobre a reorganização do sistema escolar brasileiro ensino primário, secundário e superior -, além de outros que se referiam à administração escolar. Contudo, não foi incluído, nessa reforma, o ensino profissionalizante, que estava subordinado a outro Ministério.

Convêm destacar outras duas importantes iniciativas do Ministério da Justiça e Negócios Interiores, que se vinculam à ideia de educação como instrumento de regeneração de menores por meio do trabalho. A primeira refere-se ao Decreto 16.272 , de

\footnotetext{
4 À época, os níveis de ensino primário, secundário e superior estavam subordinados Ministério da Justiça e Negócios Interiores. Já o ensino profissional era de competência do Ministério da Agricultura, Indústria e Comércio (NAGLE, 2001).
} 
20 de dezembro de 1923, que aprovava o regulamento da assistência e proteção aos menores abandonados e delinquentes.

O Decreto estabelecia que "aos menores será ministrada educação física, moral, profissional e literária" (Art. 80), sendo que a educação profissional:

[...] consistirá na aprendizagem de um ofício, adequado à idade, força e capacidade dos menores e às condições do estabelecimento. Na escolha da profissão a adotar o diretor atenderá a informação do médico, procedência urbana ou rural do menor, sua inclinação à aprendizagem adquirida anteriormente ao internamento, e ao provável destino (DECRETO 16.272, 1923, Art. 80, § 3ㅇ).

A segunda iniciativa desse Ministério foi a aprovação do Regulamento da Escola João Luiz Alves, por meio do Decreto 17.508, de 4 de novembro de 1926. Trata-se da primeira Escola de Reforma do país, destinada a receber os menores delinquentes para regenerálos por meio do trabalho, educação e instrução, oferecendo-lhes um tipo de educação diferenciada do ensino primário e secundário.

O sistema educacional lançava, assim, influência sobre outro serviço público em fase de organização nos primeiros anos da República, a assistência social. A organização desses serviços representava a forma inicial de construção da política social no Brasil, que se desenvolveu a partir dos anos de 1930.

Sobre a importância da organização e oferta desses serviços pelo Estado, Braverman (1987) afirma que, na era dos monopólios:

\begin{abstract}
O sistema escolar [...] é apenas um dos serviços que são necessariamente ampliados na industrialização e urbanização da sociedade e na forma especificamente capitalista assumida por essas transformações. A saúde pública, serviço postal e muitas outras funções públicas são igualmente desenvolvidas pelas necessidades de uma estrutura social intrincada e delicadamente equilibrada que não possui meio algum de coordenação ou planejamento social a não ser o planejamento interno e empresarial dos monopólios que proporcionam a estrutura esquelética da Economia. E muitos desses 'serviços' como prisões, polícia e 'assistência social' expandem-se extraordinariamente devido à amargurada e antagonística vida social das cidades (BRAVERMAN, 1987, p. 245).
\end{abstract}

De acordo com o autor, a oferta desses serviços públicos, dentre eles a educação e a assistência social, era necessária para "manter a vida e aliviar a insegurança" (BRAVERMAN, 1987, p. 244) da estrutura social, condicionando os homens, desde seus anos iniciais, às 
formas de adaptação ao meio. Nesta perspectiva, o Estado espraiou seu foco de intervenção, visando ao controle social da população pobre.

Desta forma, a atenção aos menores pobres tornou-se objeto não somente dos educadores, como também, de médicos e juristas, que construíram, por outras vias, uma proposta de intervenção do Estado junto a esse segmento da população. Tal proposta partiu do imbricamento entre a reflexão sobre educação e sobre o controle da população empobrecida, constituindo um novo modelo de intervenção social.

\section{A educação e a assistência aos pobres no Brasil}

No início do século XIX, as mudanças institucionais e legislativas referentes à infância e à juventude, nos países europeus e americanos, instituíram novas práticas e responsabilidades no âmbito público e também na esfera privada. Sob a influência do utilitarismo, da medicina higienista, das novas formas de exercer a filantropia e do liberalismo - pautados no progresso contínuo e na ordem social -, os modelos caritativos foram sendo combatidos, principalmente, nos países europeus, e suas ideias disseminadas em outros continentes.

Ao final desse mesmo século, as práticas caritativas, no Brasil, foram sendo fundidas, gradualmente, às práticas filantrópicas assistenciais, pautadas na cientificidade dos modelos positivos. A racionalização da assistência, através da filantropia, visava a atender as demandas impostas por uma nova ordem política, econômica e social, que ajustava as bases do Estado liberal à realidade da sociedade moderna, sob a lógica capitalista.

Com base nessa lógica, os problemas sociais foram vinculados à carência de recursos materiais e morais que possibilitam a sobrevivência dos indivíduos por própria conta. A pobreza era tida, portanto, como um problema do indivíduo, sendo este o único responsável por sua situação. Desta forma, como a pobreza é um problema individual, seu combate também é concebido como algo individual e privado, sendo valorizado, sobretudo, o caráter voluntário das ações então implementadas.

No contexto da pobreza, no Brasil, as crianças e os adolescentes foram concebidos como um problema social e tratadas como "menores". Londoño (1991) identificou, em seus estudos, que a palavra "menor" foi utilizada até o século XIX para expressar, juridicamente, os menores de idade. Aos poucos, o termo foi adquirindo uma conotação diferenciada 
diante do expressivo número de crianças e adolescentes que perambulavam pelas ruas dos grandes centros urbanos, evidenciando comportamentos antissociais. Conforme assinala o autor:

\begin{abstract}
No fim do século XIX, olhando para o seu próprio país, os juristas brasileiros descobrem o 'menor' nas crianças e adolescente pobres das cidades, que por não estarem sob a autoridade dos seus pais e tutores são chamadas pelos juristas de abandonadas. Eram, pois, menores abandonados as crianças que povoavam as ruas dos centros das cidades, os mercados, as praças e que por incorrer em delitos frequentavam o xadrez e as cadeias, neste caso passando a serem chamados de menores criminosos (LONDOÑO, 1991, p. 134-135).
\end{abstract}

Assim, o termo "menor" foi apropriado por juristas e médicos sanitaristas como sinônimo de mendicância, vadiagem e delinquência, diante do abandono material e moral. Juristas da época, como Cândido Nogueira da Motta e Evaristo de Moraes, assinalavam que os menores não eram somente abandonados por suas famílias, mas, principalmente, pelo Estado, “[...] que os ignorava e tratava como simples caso de polícia” (LONDOÑO, 1991, p. 135).

No início do século $\mathrm{XX}$, a situação dos menores tornou-se evidente a partir dos debates levantados entre médicos e juristas, demandando ações pontuais do Estado com larga responsabilidade filantrópica. Moncorvo Filho $^{5}$, médico pediatra, foi um dos baluartes da época que se dedicaram à questão da infância no Brasil. O Instituto de Proteção $e$ Assistência à Infância, inaugurado em 14 de julho de 1901, na cidade do Rio de Janeiro, a partir de suas idealizações, foi reproduzido em diversas regiões do país ${ }^{6}$.

A missão higienista, de caráter científico-filantrópica da medicina, foi defendida por vários médicos e juristas daquele período, que identificaram a necessidade de expansão da atuação do Estado sobre focos de desordem e doença, de modo a interferir no ambiente familiar pobre por meio de uma educação moralizadora.

\footnotetext{
5 Carlos Arthur Moncorvo Filho (1871-1944) é reconhecido como um dos pioneiros da Puericultura no Brasil e precursor das políticas de proteção à infância no país. Em 1899, fundou o Instituto de Proteção e Assistência à Infância, inaugurado apenas em 1901, e em 1919, criou, com recursos próprios, o Departamento da Criança no Brasil, promovendo os Congressos Brasileiros de Proteção à Infância. Publicou diversos artigos científicos sobre pediatria e três livros considerados obras de referência para a história da pediatria no Brasil: Hygiene Infantil (1917), Formulário de Doenças das Crianças (1923) e Histórico da Proteção à Infância no Brasil (1926). Criou, ainda, a revista Archivos de Assistência à Infância (1902). Foi nomeado presidente da Sociedade Brasileira de Pediatria em 1933 (MARTINS; CAMPOS JÚNIOR, 2007).

${ }^{6}$ Minas Gerais (1904); Curitiba, Rio Grande do Sul e Pernambuco (1906); Santos (1914).
} 
Desta forma, à esfera pública e, portanto, ao Estado, pertencia a responsabilidade de controlar e prevenir apenas aqueles episódios e eventos que ameaçavam a ordem pública, ou seja, a segurança da população.

Tratava-se, conforme expõe Cohn (2000), de uma atuação pautada no que se considerava tolerável e intolerável enquanto problema social. A pobreza seria tolerável para a sociedade quando não se associasse, por exemplo, à violência. O que era considerado "normal", como a pobreza, tornava-se patológico, portanto, intolerável, quando associado à violência, o que exigia a ação do Estado.

O meio social, ou melhor, a pobreza, configurou-se como o cenário que conduziu crianças e adolescentes a atividades ilícitas e a comportamentos antissociais, assim, necessitavam, conforme reforçavam juristas e médicos da época, de uma intervenção estatal que viesse prevenir tais comportamentos.

Embalados por estudos europeus sobre a criminalidade, médicos e juristas desenvolveram suas propostas reformadoras, privilegiando ações sobre a infância e a juventude pobres, a fim de atingir o ideal de modernização e progresso, por meio da manutenção da ordem. A educação, como instrumento capaz de ordenar e moralizar uma sociedade, foi defendida pelos reformadores sociais sob a premissa de que "salvar a criança era salvar a nação" (RIZZINI, 2008, p. 27), definida por Rizzini (2008, p.20), em sua crítica, como um "discurso salvacionista".

A educação moral começava no lar, mas quando este não tinha condições materiais e morais para realizá-la, a criança deveria ser retirada do ambiente familiar. O aumento de habitações consideradas inadequadas, aglomeradas em cortiços, identificou o ambiente familiar como um local nocivo à formação do caráter da criança que se encontrava abandonada material e moralmente.

De acordo com o jurista Alvarenga Netto (1941):

Êsse problema da habitação é o problema das capitais, das metrópoles. E, quando ao par da miséria, da falta de higiene física, se encontra a ausência da higiene moral, certo a criança que se desenvolve em meio tão deletério e corrupto, terá o seu caráter modelado, plasmado pelos exemplos das figuras que a rodeiam. [...]. Nessas habitações, nesses antros, onde o pudor da menina se estióla e com sua miséria física se desenvolve a miséria moral, formam-se as libertinas, que, moças, se transferem depois para os prostíbulos. Dali saem também os meninos viciados ao comêço, delinquentes ao fim, que, homens depois, povoam os presídios (ALVARENGA NETTO, 1941, p. 17-18). 
O autor destacava ainda que:

Questão assim, de magna importância para a educação moral da criança, constitui a casa, o ambiente familiar. Está demonstrada a nocividade dos aglomerados, da promiscuidade nas habitações coletivas, onde o vício e as tendências condenáveis encontram fácil expansão ou propagação (ALVARENGA NETTO, 1941, p. 15).

O jurista enfatizava que a assistência ao menor deveria começar por seu isolamento do ambiente pernicioso, pois o identificava como um espaço de proliferação de uma doença social chamada criminalidade.

Já Franco Vaz, diretor da Escola Premonitória 15 de Novembro, utilizando termos médicos, identificou, na educação, a vacina para prevenir a criminalidade infantil:

[...] quando os problemas materiais de hygiene publica teem, hoje, invariavelmente, a sua prophylaxia, a sua serotherapia, precisamos ter diante de nossos olhos a verdade inilludivel de que a prophylaxia das enfermidades moraes de uma sociedade pôde e deve também fundar-se em outra espécie de serotherapia e, dentro desta, a verdadeira vacina preventiva da crimnalidade é a educação. E quanto melhor fôr a qualidade do respecitvo soro, mais seguros e eficazes serão seus efeitos (FRANCO VAZ apud LONDOÑO, 1991, p. 142. Grifos nossos).

Em meio às diversas mazelas sociais, a criança foi percebida através de um olhar paradoxal: de um lado, ela representava o futuro do país, de outro, um perigo à ordem social. Por essa lógica, entende-se que, se bem educada, a criança seria útil para a sociedade, mas, caso a família não conseguisse desempenhar seu papel disciplinador, a criança seria uma ameaça social, devendo ser retirada do meio e reeducada, para que assim tivesse utilidade (RIZZINI, 2008).

Desta forma, tornava-se cada vez mais necessária uma intervenção do Estado diante do problema social dos menores carentes. A pressão pela mudança de posicionamento do Estado - que até então não agia diretamente sobre as questões da infância e da juventude - contribuiu para a criação de diversos decretos que regulamentaram a proteção e a assistência aos menores no Brasil.

A necessidade de uma mudança legal na atuação do Estado, em relação à proteção do menor, foi enfatizada por muitos juristas da época. A pressão pela existência de 
estabelecimentos destinados à proteção de menores e pela instituição de um direito do menor contribuiu para que os debates dispersos da época fossem convertidos em discussões objetivas sobre a organização da assistência aos menores.

As discussões centravam-se na importância de educar e formar os menores conforme as necessidades da sociedade daquele momento, no sentido de prevenir a criminalidade e garantir a ordem social, conforme observou o jurista Cândido Nogueira da Motta:

Ora, é inegável que, protegendo a infância abandonada, guiando os seus passos, encaminhando-a para o trabalho honesto, capaz de assegurar o futuro, o Estado, se por um lado preserva essa infância das más tendências, por outro, previne a sociedade dos maus elementos (MOTTA apud LONDOÑO, 1991, p. 141).

Londoño (1991) assinala que a criminalidade deveria ser prevenida por meio de esforços que garantissem a educação e a formação da índole e do caráter, com base em um sistema de medidas preventivas e corretivas. A prevenção supunha a necessidade de se retirar o menor do ambiente desorganizado e das ruas, e colocá-lo em escolas correcionais com o propósito de suprir sua carência moral e material e educá-lo para a vida em sociedade, disciplinando-o para o trabalho.

Desta forma, dentre as iniciativas legais do Estado, a aprovação da Lei Orçamentária 4.242, de 05 de janeiro de $1921^{7}$, foi o primeiro passo para a implantação de um Plano de Assistência e Proteção à Infância no Brasil.

Em 20 de dezembro de 1923, sob o governo de Arthur da Silva Bernardes, foi aprovado o Regulamento da Assistência e Proteção aos menores abandonados e delinquentes, por meio do Decreto $n$ 0 16.272. Tal decreto, além de representar os anseios da educação, tendo como ideal a regeneração pelo trabalho, foi um importante instrumento jurídico para a organização da assistência no Brasil. Para fins legais, a assistência e a proteção de menores foram dirigidas a todos os menores de idade, independente do sexo, que se encontravam em situação de abandono e delinquência.

\footnotetext{
${ }^{7}$ Lei Orçamentária que fixou as despesas em relação à organização da assistência e proteção à infância abandonada e delinquente no Brasil, para o ano em vigência, durante o Governo do Presidente Epitácio Pessoa. Esta Lei foi revigorada e ligeiramente modificada em 1922, pelo Decreto no 4.547, de 22 de maio de 1922. Ver MARQUES, Joaquim Candido de Azevedo. Menores abandonados e delinquentes. São Paulo: Saraiva \& C. a Editores, 1925.
} 
Em 1926, por meio do Decreto no. 5.083, de 01 de dezembro, foi instituído o Código de Menores, durante o governo de Washington Luis, que adicionou dispositivos para consolidar as leis de assistência e proteção aos menores. Porém, foi somente com o Decreto no. 17.943-A, de 12 de outubro de 1927, conhecido como Código Mello Mattos ${ }^{8}$, que as leis de assistência e proteção aos menores foram, realmente, consolidadas. Este Código regulamentou todas as ações desenvolvidas na área da assistência e proteção aos menores até 1979, ano em que foi revogado e instituído um novo Código de Menores.

Ao se comparar os três últimos decretos, observa-se que a redação foi, consideravelmente, modificada em alguns itens. Entretanto, os três decretos destinavamse à adoção de medidas necessárias à guarda, tutela, vigilância, educação, preservação e reforma dos menores abandonados e delinquentes.

Sobre a situação de abandono, Alvarenga Netto (1941) alertava que esta não correspondia somente à falta de recursos materiais, pois o abandono moral poderia ocorrer também nas classes mais abastadas:

É preciso que se tome aqui o vocábulo abandonado, na verdadeira acepção jurídica e social, porque, menores há que, nem por terem assistência higiênica, alimentar e econômica, enfim, deixam de estar abandonados, por quanto thes falta assistência espiritual e os cuidados necessários para sua formação moral. Não só nas classes menos favorecidas da fortuna, das classes pobres ou miseráveis, encontra-se o menor moralmente abandonado, mas também nas classes abastadas ou ricas mesmo (ALVARENGA NETTO, 1941, p. 14. Grifos do autor).

Embora o jurista considere que o abandono moral independe da situação financeira, os três decretos foram enfáticos em considerar como situações de abandono material e moral aquelas que ocorrem, habitualmente, em casos de prática de vadiagem, mendicância ou libertinagem.

Quanto à distinção entre menores abandonados e delinquentes, subentende-se que todos os menores abandonados estavam predispostos à delinquência, conforme expunha Alvarenga Netto (1941, p. 47): “Do abandono ao crime, a distância é pequena”.

Os decretos apenas diferenciavam a idade quanto às medidas aplicadas, quando o menor for "indigitado autor ou cúmplice de fato qualificado como crime ou contravenção

\footnotetext{
8 Primeiro Juiz de Menores, Mello Mattos foi o mentor do Código de Menores de 1927. Por este motivo, o Código também é conhecido como Código Mello Mattos.
} 
penal" (Código de Menores, 1927. Art. 68 e 69). No caso de menores de 14 anos, estes não seriam submetidos a processo judicial, devendo ser entregues aos responsáveis ou internados em institutos educacionais; e no caso de maiores de 14 anos, o processo seria realizado de acordo com a Lei e o menor internado em Escola de Reforma pelo período de um a sete anos.

No Distrito Federal, a disciplina dos menores abandonados e dos criminosos ficou a cargo, a princípio, da Escola Premonitória 15 de Novembro . Em 1926, o Presidente Arthur Bernardes instituiu a Escola de Reforma João Luiz Alves e aprovou seu regulamento por meio do Decreto no. 17.508, de 04 de novembro de 1926, destinando-a apenas aos menores delinquentes. Nos demais estados, foram criados abrigos e institutos disciplinares.

\section{Considerações finais}

O Estado começou a intervir, de forma direta, na questão dos menores abandonados, vadios e delinquentes, por meio da criação de Institutos Educacionais, Escolas de Reforma e Patronatos ${ }^{10}$, com serviços especializados em quase todos os estados do país.

A criação de tais estabelecimentos exigiu a participação de saberes médicos, jurídicos e pedagógicos para a oferta de serviços especializados que atendessem ao objetivo de assistir e proteger os menores abandonados e delinquentes, por meio de práticas disciplinares, tendo o trabalho como seu valor central.

A medicina, com base nos saberes da puericultura e dos higienistas, contribuiu para identificar medidas relacionadas à saúde, à nutrição e à higiene dos menores. Assim, em todas as instituições educativas, havia profissionais da saúde, como médicos, enfermeiros e dentistas, no quadro de pessoal.

Os saberes jurídicos edificaram leis de assistência e proteção aos menores, fornecendo os subsídios legais para a implantação das Escolas de Reforma e Patronatos, as quais deveriam instruir e disciplinar os menores, por meio de práticas pedagógicas.

\footnotetext{
${ }^{9}$ A Escola Premonitória 15 de Novembro tinha por finalidade ministrar assistência e educação física, moral e profissional aos menores abandonados, de acordo com o art. 7ํ da Lei n 947, de 29 de dezembro de 1902 (PAIVA, 1916).

${ }^{10}$ Os patronatos, instituições previstas na legislação penal, remetem à ideia de proteção, sendo o termo derivado de patrono, que segundo o Dicionário Houaiss (2009) refere-se ao "[...] que luta ou defende uma causa, protetor".
} 
Ao setor pedagógico ficou com a responsabilidade de criar medidas de disciplina, além de contribuir para a instrução dos menores e prepará-los para sua reintegração na sociedade.

Assim, o Estado incrementou seu aparato jurídico e assistencial para a proteção à infância abandonada, nas primeiras décadas do século XX. As ações voltadas para este segmento foram planejadas de forma a discipliná-lo, moldando seus hábitos e costumes a uma sociedade de tipo capitalista, tendo no trabalho o seu valor principal.

A educação foi referenciada como principal forma para atingir o ideal de uma sociedade civilizada e moderna. Médicos e juristas enfatizaram a importância de uma educação moralizadora, que viesse a prevenir a criminalidade infantil. Para tanto, seria necessário criar, ainda, além de instituições com o intuito de educar e disciplinar as crianças e adolescentes pobres e introjetar os valores dessa "nova nação", institutos específicos para a reeducação dos menores delinquentes, ou seja, as Escolas de Reforma. As ideias que sustentaram esse modelo de Escola para menores delinquentes encontram-se descritas em obras de grandes juristas da época, tais como Ataulpho de Paiva, Noé Azevedo e Evaristo de Moraes, que justificaram a importância de uma educação assistencial, voltada para os menores delinquentes, precursora de todo aparato socioeducativo existente nos dias de hoje.

\section{Referências}

BRASIL. Lei Federal n. 4.242, de 05 de janeiro de 1921. In: MARQUES, Joaquim Candido de Azevedo. Menores abandonados e delinquentes. São Paulo: Saraiva e Cia, 1925.

BRASIL. Decreto n. 16.272, de 20 de novembro de 1923. In: MORAES, Evaristo de. Criminalidade da Infância e da Adolescência. 2a ed. Rio de Janeiro: Livraria Francisco Alves, 1927.

BRASIL. Decreto n. 17.508, de 04 de novembro de 1926. Regulamento da Escola João Luiz Alves. In: In: MORAES, Evaristo de. Criminalidade da Infância e da Adolescência. 2a ed. Rio de Janeiro: Livraria Francisco Alves, 1927.

BRASIL. Decreto n. 17. 943-A, de 12 de outubro de 1927. In: NETTO, Alvarenga. Código de Menores. Doutrina, legislação, jurisprudência. 2a ed. Rio de Janeiro: Livraria Editora Freitas Bastos, 1941.

BRAVERMAN, Harry. Trabalho e capital monopolista: a degradação do trabalho no século XX. Rio de Janeiro: Livros Técnicos e Científicos Editora, 1987. 
CAMBI, Franco. História da pedagogia. Trad. Álvaro Lorencini. São Paulo: Fundação Editora da Unesp (FEU), 1999.

CARLOS, Viviani Yoshinaga. Escolas de Reforma: um estudo sobre as ideias que sustentaram a sua organização no Brasil. 2013. 143f. Dissertação (Mestrado em Serviço Social e Política Social) - Universidade Estadual de Londrina, Londrina, 2013.

COHN, Amélia. A questão social no Brasil: a difícil construção da cidadania. In: MOTA, Carlos Guilherme (org). Viagem incompleta: a experiência brasileira (1500-2000): a grande transição. São Paulo: Editora SENAC, 2000, p. 385-403.

CUNHA, Luiz Antônio Constant Rodrigues da. A educação e a construção de uma sociedade aberta. In: . Educação e desenvolvimento social no Brasil. Rio de Janeiro: Francisco Alves, 1975. O ensino de ofícios artesanais e manufatureiros no Brasil escravocrata. São Paulo: Editora UNESP; Brasília, DF: Flacso, 2000.

CURY, Carlos Roberto Jamil. A desoficialização do ensino no Brasil: a Reforma Rivadávia. Educ. Soc., Campinas, vol. 30, n. 108, out. 2009, p. 717-738. Disponível em <http://www.cedes.unicamp.br>. Acesso em 12 de fevereiro de 2013.

DICIONÁRIO HOUAISS. Verbete "Patrono". Dicionário eletrônico. Instituto Antonio Houaiss. Editora Objetiva, 2009.

LONDOÑO, Fernando Torres. A origem do conceito Menor. In: DEL PRIORE, Mary. História da criança no Brasil. São Paulo: Contexto, 1991. p. 129-145.

MARQUES, Joaquim Candido de Azevedo. Menores abandonados e delinquentes. São Paulo: Saraiva \& C. Editores, 1925.

MARTINS, Reinaldo Menezes; CAMPOS JÚNIOR, Dioclécio. História da pediatria no Brasil. Disponível em: http://www.manole.com.br. Acesso em: 15 de julho de 2008.

NAGLE, Jorge. Educação e sociedade na Primeira República. 2ed. Rio de Janeiro: DP\&A, 2001.

NETTO, Alvarenga. Código de Menores. Doutrina, legislação, jurisprudência. 2a ed. Rio de Janeiro: Livraria Editora Freitas Bastos, 1941.

NETTO, José Paulo. Capitalismo monopolista e Serviço Social. 3a ed. ampliada. São Paulo: Cortez, 2001.

PAIVA, Ataulpho de. Justiça e assistência: os novos horizontes. Rio de Janeiro: Typ. do jornal do Commercio, 1916.

PONCE, Aníbal. Educação e luta de classes. Trad. José Severo de Camargo Pereira. 18ed. São Paulo: Cortez, 2001. 
RIZZINI, Irene. O século perdido: raízes históricas das políticas públicas para infância no Brasil. 2 ed. São Paulo: Cortez, 2008.

RIZZINI, Irma. Meninos desvalidos e menores transviados: a trajetória da assistência pública até a Era Vargas. In: RIZZINI, Irene; PILOTTI, Francisco. A arte de governar crianças. 2 ed. São Paulo: Cortez, 2009.

XAVIER, Maria Elizabete Sampaio Prado. Capitalismo e escola no Brasil. A constituição do liberalismo em ideologia educacional e as reformas do ensino (1931-1961). Campinas, SP: Papirus, 1990 